\title{
Intraocular eyelash after uneventful cataract surgery
}

This article was published in the following Dove Press journal:

Clinical Optometry

31 March 2010

Number of times this article has been viewed

\section{Boris Knyazer \\ Jaime Levy \\ Itamar Klemperer \\ Tova Lifshitz \\ Department of Ophthalmology, Soroka University Medical Center, Ben-Gurion, University of the Negev, Beer-Sheva, Israel}

Correspondence: Boris Knyazer Department of Ophthalmology, Soroka University Medical Center, P.O. Box I5184101 Beer-Sheva, Israel Tel +97286400379

Fax +97286403927

Email knyazer@bgu.ac.il
Introduction: Intraocular eyelash is an uncommon complication after cataract surgery. We report a very rare case of corneal foreign body after uneventful phacoemulsification surgery.

Methods: A 66-year-old man referred to our outpatient ophthalmology clinic for routine examination one week after uneventful phacoemulsification cataract extraction in the left eye. Slit-lamp examination revealed a cilium in the anterior chamber with the proximal end abutting on the inner ostium and the distal end freely mobile in the external ostium of the 6 o'clock paracentesis.

Results: The eyelash was removed under topical anesthesia with toothless forceps. Follow-up examinations were unremarkable.

Conclusion: Intraocular eyelash is an uncommon complication after modern cataract surgery. Early detection and removal lead to a favorable outcome and prevent possible postoperative inflammation or infection.

Keywords: eyelash, intraocular, foreign body, phacoemulsification, cataract

\section{Introduction}

One common cause of admittance to emergency wards and ophthalmic clinics is corneal or conjunctival foreign body. Many types of foreign bodies can be embedded or penetrate into the cornea. We herein report a curious case of corneal foreign body after uneventful phacoemulsification cataract surgery. The foreign body was the patient's own eyelash that had migrated through the clear cornea paracentesis site.

\section{Case report}

A 66-year-old man referred to our outpatient ophthalmology clinic for routine examination one week after uneventful phacoemulsification cataract extraction in the left eye. According to the patient's files, the course of operation and one day postoperative examination were unremarkable. After the operation the patient was treated with ofloxacin (Oflox) and dexamethasone $0.1 \%$ (Sterodex $\left.{ }^{\circledR}\right)$ drops four times a day. At examination, best-spectacle corrected visual acuity (BSCVA) was 20/40. The patient did not have any eye complaints. Slit-lamp examination revealed mildly reddish bulbar conjunctiva and an eyelash in the anterior chamber protruding through the paracentesis site used for the anterior chamber maintainer at the 6 o'clock position. On review, a cilium was detected in the anterior chamber with the proximal (follicle) end abutting on the inner ostium and the distal (tip) end freely mobile in the external ostium of the 6 o'clock paracentesis (Figure 1). No leakage was detected. A mild inflammatory reaction (flare +1 ) was observed in the anterior chamber. The intraocular pressure was $13 \mathrm{mmHg}$ in the left eye. The posterior segment was normal. The eyelash was removed 


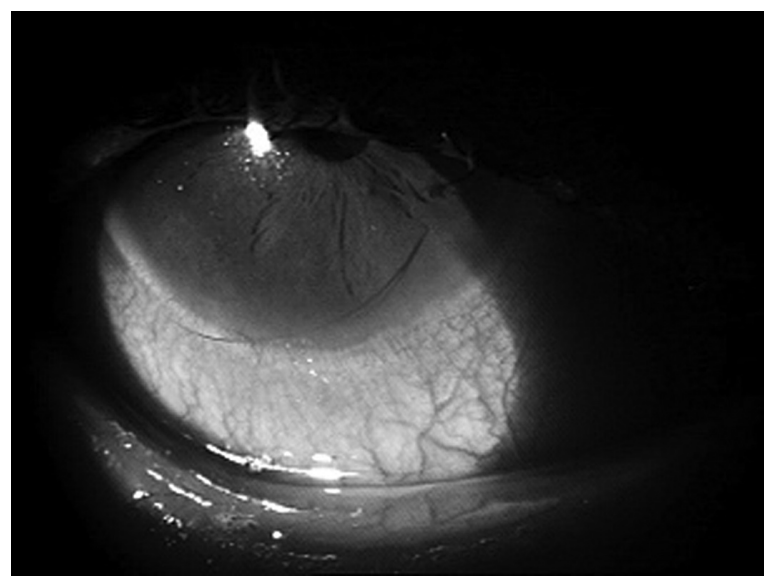

Figure I Eyelash detected in the anterior chamber with the proximal end abutting on the inner ostium and the distal end freely mobile in the external ostium of the 6 o'clock paracentesis.

under topical anesthesia with a toothless forceps (Figure 2) and topical antibiotics and steroids were continued. The paracentesis site was carefully inspected and found to be Seidel negative. Follow-up examinations were unremarkable. BSCVA three months after the operation was 20/20 and the complete cornea was clear.

\section{Discussion}

Many different types of foreign bodies can enter the cornea. These may include windblown grit, fragments of glass, metal filings, vegetable matter, or insect parts. ${ }^{1}$ Numerous unusual

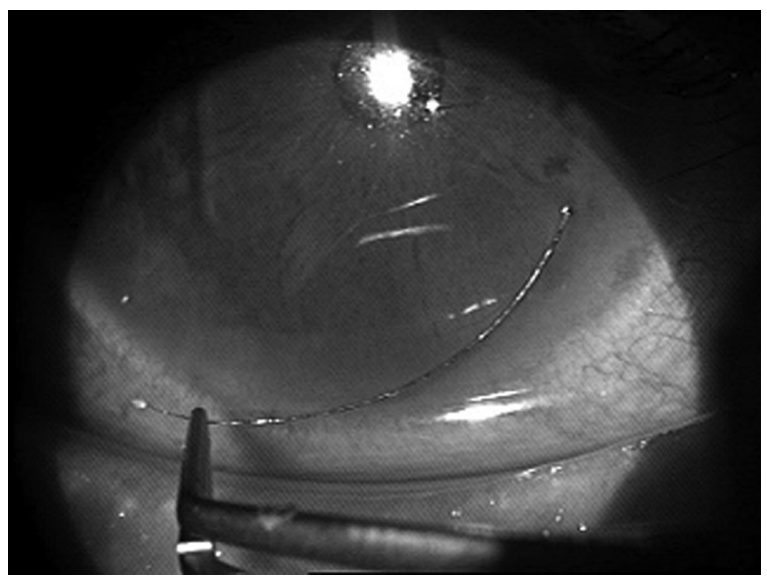

Figure 2 The eyelash was removed under slit-lamp magnification using toothless forceps. intraocular foreign bodies have been described in the literature: caterpillar setae, Filaria worms, peanut oil, and even a germinating seed in the anterior chamber. ${ }^{2}$ Eyelash as intracorneal foreign body is a very uncommon complication after small-incision phacoemulsification. A Medline ${ }^{\circledR}$ search using the United States National Library of Medicine PubMed ${ }^{\circledR}$ online database, conducted in October 2009, showed only three reports of eyelashes migrating into clear corneal paracenteses. $^{3-5}$ In one of the cases the cilium migrated to the anterior chamber ${ }^{3}$ and in the other two cases it remained embedded into the paracentesis site. ${ }^{4,5}$ Several mechanisms of eyelash entry have been proposed. Rofail et $\mathrm{al}^{3}$ hypothesized that eye rubbing was able to distort the incision with significant manual pressure directly to the globe and allow cilium to be entrapped in a corneal wound after uneventful small-incision cataract surgery. In addition, blinking and eyelid squeezing have been shown to result in dramatic intraocular pressure fluctuation and may have resulted in alteration of the incision to allow the lash entrance. ${ }^{5}$

As mentioned, intraocular eyelash is an uncommon complication after phacoemulsification. This curious finding perhaps may be seen more frequently in clinical practice, but is rarely reported in the literature. Early detection and removal will lead to a favorable outcome and prevent postoperative inflammation or infection of the paracentesis site and consequent postoperative keratitis, uveitis, or endophthalmitis.

\section{Disclosures}

The authors have no proprietary interest in any of the materials or techniques used in this study. No financial support has been received for the preparation of this manuscript.

\section{References}

1. Fogla R, Rao SK, Anand AR, Madhavan HN. Insect wing case: unusual foreign body. Cornea. 2001;20:119-121.

2. Abel S. Germinating seed in anterior chamber. Report of an unusual case. Arch Ophthalmol. 1979;97:1651.

3. Rofail M, Briner AM, Lee GA. Migratory intraocular cilium following phacoemulsification. Clin Experiment Ophthalml. 2006;34:78-80.

4. Walker NJ, Hann JV, Talbot AW. Postoperative cilium entrapment by clear corneal incision. J Cataract Refract Surg. 2007;33:733-734.

5. Etter J, Kim T. Eyelash migration into a clear corneal incision following cataract surgery. J Cataract Refract Surg. 2008;34:1417-1418.
Clinical Optometry

\section{Publish your work in this journal}

Clinical Optometry is an international, peer-reviewed, open access journal publishing original research, basic science, clinical and epidemiological studies, reviews and evaluations on clinical optometry. All aspects of patient care are addressed within the journal as well as the practice of optometry including economic and business analyses. Basic and clinical research papers are published that cover all aspects of optics, refraction and its application to the theory and practice of optometry. The manuscript management system is completely online and includes a very quick and fair peer-review system, which is all easy to use. Visit http://www.dovepress. com/testimonials.php to read real quotes from published authors. 